\title{
OSTEOPOIOULOSE-APRESENTAÇÃODEUMCASOEREVSÃO DALTERATURA*
}

\author{
Antonio Carlos Pires Carvalho ${ }^{1}$, Rodrigo Santos Beze ${ }^{2}$, Sérgio Estevam Picinini ${ }^{3}$
}

\begin{abstract}
Resumo Os autores relatam o caso de uma paciente portadora do HIV e tuberculose pulmonar, na qual foram observadas alterações ósseas compatíveis com osteopoiquilose. A osteopoiquilose foi diagnosticada por acaso. São mostradas imagens do estudo por radiologia convencional e tomografia computadorizada, e breve revisão da literatura. Que seja do nosso conhecimento, trata-se do primeiro relato desta associação de doenças. Unitermos: Osteopoiquilose. HIV. Radiologia.
\end{abstract}

Abstract Osteopoikilosis - a case report and review of the literature.

The authors report a case of osteopoikilosis in a woman with HIV infection and pulmonary tuberculosis, and bone abnormalities suggestive of osteopoikilosis. The diagnosis of osteopoikilosis was incidental. Plain films and computed tomography images as well as a review of the literature are presented. To our knowledge this is the first report of association of these diseases.

Key words: Osteopoikilosis. HIV. Radiology.

\section{INTRODUÇÃO}

A osteopoiquilose é uma displasia osteosclerótica, assintomática, também conhecida como osteopatia condensante disseminada ou doença do osso manchado ${ }^{(\mathbf{1})}$. Descrita no início do século por Stieda, Albers-Schönberg e Ledoux-Lebard, costuma ser um achado radiológico em investigação de doença concomitante ${ }^{(2)}$.

\section{RELATO DO CASO}

Paciente do sexo feminino, 23 anos de idade, solteira, parda, natural de Minas Gerais, com queixas de tosse, fraqueza e relatando convivência com parceiro HIVpositivo. Apresentava, ao exame físico, estertores crepitantes na base do hemitórax direito.

Foi realizada radiografia do tórax em póstero-anterior (Figura 1), que evidenciou imagem de consolidação de limites imprecisos inferiormente e definidos na área de

* Trabalho realizado no Hospital Geral de Nova Iguaçu e no Hospital Universitário Clementino Fraga Filho da Universidade Federal do Rio de Janeiro (UFRJ), Rio de Janeiro, RJ.

1. Professor Adjunto Doutor do Departamento de Radiologia da Faculdade de Medicina da UFRJ, Coordenador Adjunto de Radiodiagnóstico da Pós-Graduação em Radiologia da UFRJ.

2. Médico Residente em Radiologia da UFRJ.

3. Médico Residente em Ortopedia da UFRJ.

Endereço para correspondência: Prof. Dr. Antonio Carlos Pires Carvalho. Rua Pereira Nunes, 71, C-01. Rio de Janeiro, RJ, 20511-120. E-mail: acpcrj@ hucff.ufrj.br

Recebido para publicação em 6/4/2001. Aceito, após revisão, em 1/10/2001.

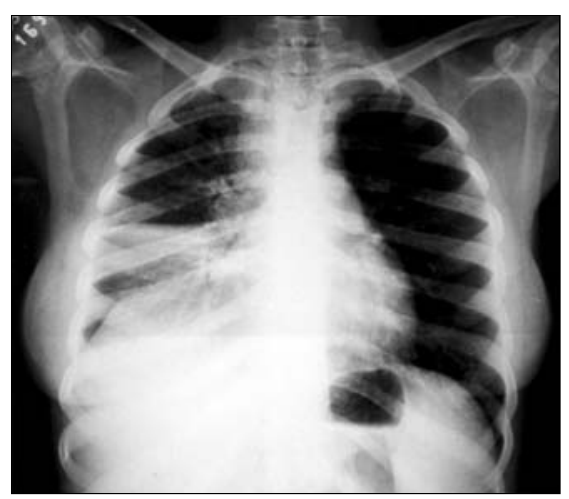

Figura 1. Radiografia de tórax em póstero-anterior mostrando consolidação de limites imprecisos no lobo inferior direito e múltiplas áreas de osso denso nos ombros.

contato com a superfície cissural, assim como numerosas áreas de osteosclerose, arredondadas, de diâmetros variados, localizadas nas epífises e metáfises proximais dos úmeros.

Foram solicitadas pesquisas de BAAR no escarro e anti-HIV, sendo feito o diagnóstico de tuberculose pulmonar em paciente HIV-positivo.

Foram realizadas radiografias de mãos, pés, ombros (Figura 2) e bacia, que evidenciaram imagens semelhantes na bacia, epífises e metáfises proximais dos fêmures (Figura 3), e em pequeno número nas mãos e pés (Figura 4), o que habitualmente não é observado na literatura consultada. Também foi realizado estudo por tomografia computadorizada das lesões dos ombros e bacia (Figura 5), que mostrou numerosas

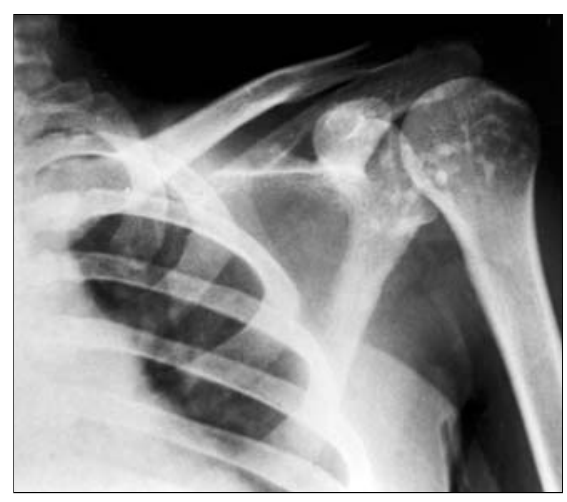

Figura 2. Radiografia do ombro esquerdo mostrando múltiplas áreas de osteosclerose arredondadas na epífise do úmero e na omoplata.

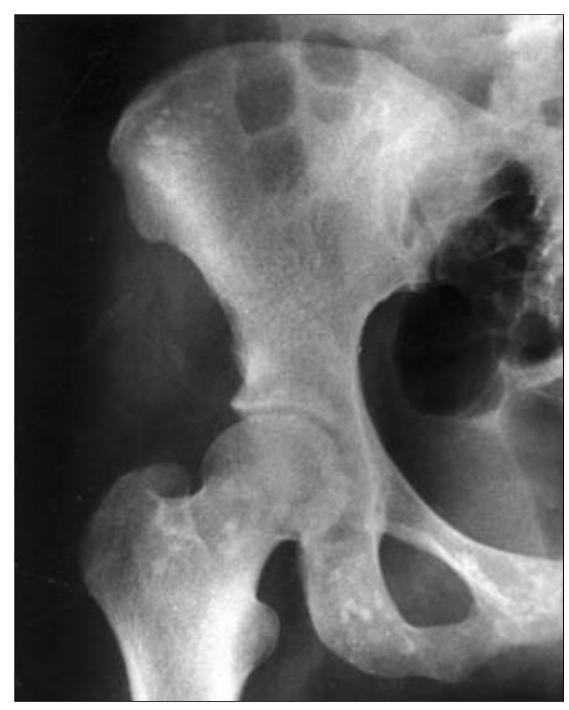

Figura 3. Radiografia do quadril direito mostrando lesões semelhantes na região proximal do fêmur, ilíaco e ramos pubianos. 

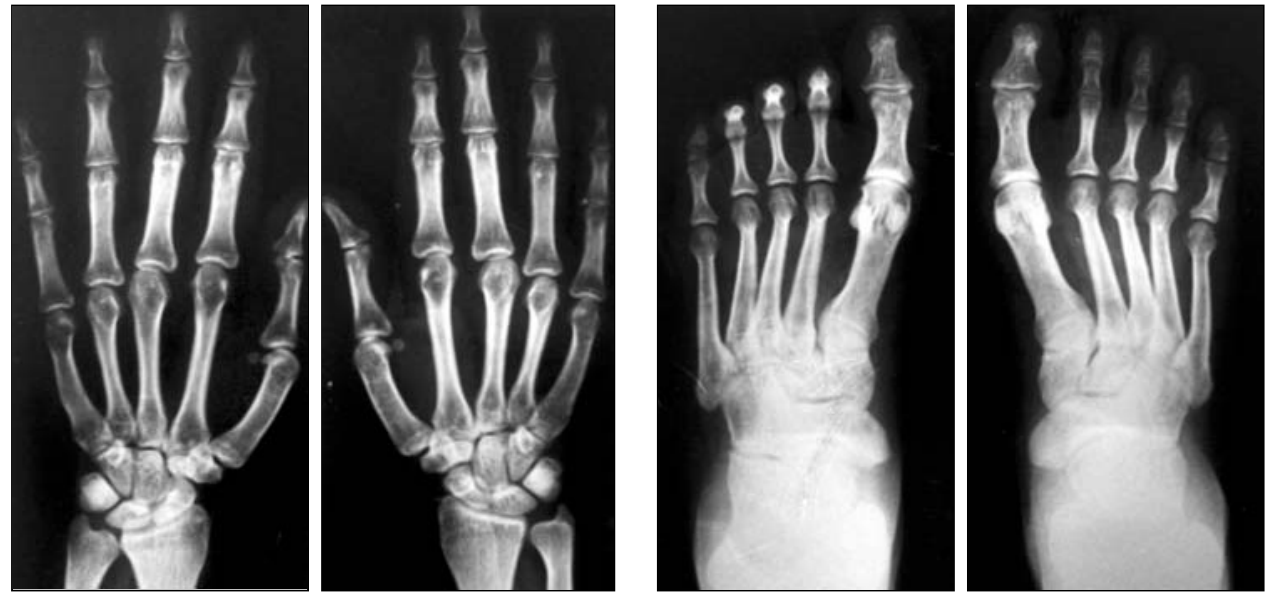

Figura 4. Radiografias de mãos e pés mostrando pequeno número de lesões osteoblásticas, pequenas e arredondadas, achado pouco comum na osteopoiquilose.
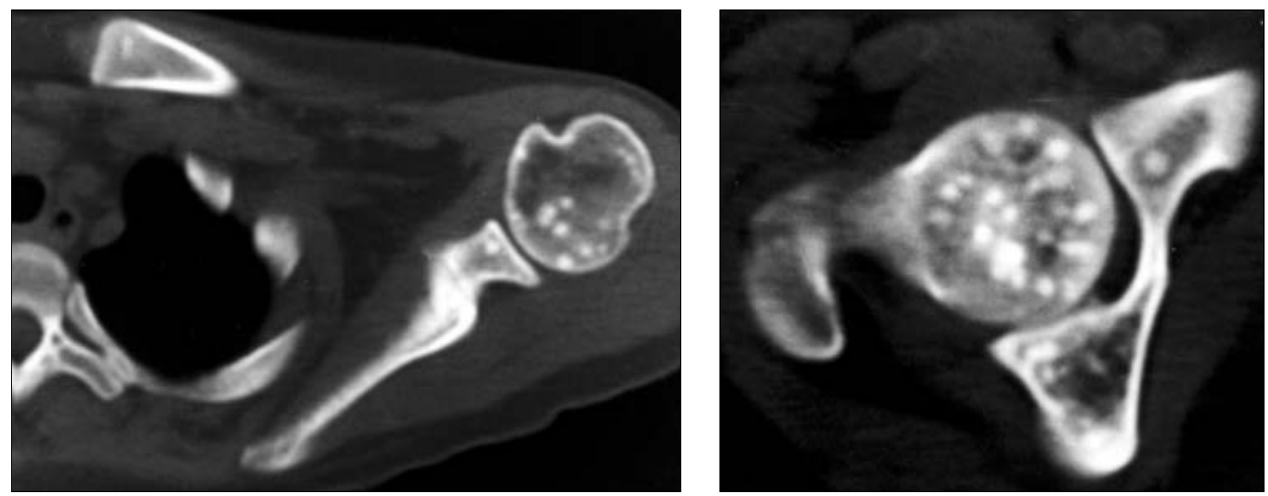

Figura 5. Tomografia computadorizada do ombro esquerdo e quadril direito mostrando múltiplas lesões arredondadas, osteocondensantes, no úmero, omoplata, clavícula, fêmur e região periacetabular.

áreas circunscritas, pequenas, arredondadas e ovaladas, de densidade óssea aumentada, esparsas nas regiões metafisária e epifisária dos ossos acometidos.

Após cuidadosa anamnese, não se obteve qualquer queixa clínica nos antecedentes pessoais da paciente. Relatou que os pais são falecidos, de causa desconhecida. Tem seis irmãos, com os quais não tem contato há vários anos. Tem um filho aparentemente saudável.

Não se encontraram evidências de uma relação direta entre as doenças.

\section{DISCUSSÃO}

A osteopoiquilose é uma alteração óssea rara, hereditária, autossômica dominante $\mathrm{e}^{(\mathbf{1 , 3})}$, habitualmente sem sintomas, caracterizando-se radiologicamente por múltiplas imagens radiopacas, arredondadas ou ovaladas, de dimensões variadas e que são mais comuns nas regiões periarticulares. Apresenta, na maioria das vezes, distribuição simétrica, com predileção por epífises e metáfises dos ossos longos tubulares, carpo, tarso, pelve e escápula. O envolvimento de costelas, clavículas, vértebras e crânio é raro ${ }^{(4)}$.

Mais freqüentemente, as lesões surgem na infância e persistem por toda a vida ${ }^{(\mathbf{1})}$, podendo variar em tamanho, número e até mesmo desaparecer ${ }^{(4)}$.

$\mathrm{O}$ estudo com radiofármacos específicos para osso não mostra atividade aumentada nas áreas com as alterações ósseas ${ }^{(4)}$.

Histologicamente, as áreas escleróticas são condensações focais de osso compacto lamelar dentro da esponjosa ${ }^{(\mathbf{1})}$. Os achados microscópicos das lesões são idênticos aos encontrados nas ilhotas ósseas.

O diagnóstico diferencial deve ser feito principalmente com metástases osteoblásticas, que vão apresentar aumento de atividade ao estudo cintilográfico. Também devem ser consideradas a mastocitose, a esclerose tuberosa, a encondromatose e a melorreostose $^{(\mathbf{4})}$.

Foram relatados casos em que esta condição estava associada a osteossarcoma ${ }^{(5)}$, condrossarcoma $^{(6)}$ e tumor de células gigantes $^{(3)}$. Também existem relatos de ou- tras associações com osteopoiquilose ${ }^{(7,8)}$, embora não seja demonstrada uma relação entre as doenças.

\section{REFERÊNCIAS}

1. Benli IT, Akalin S, Boysan E, Mumcu EF, Kis M, Türkoglu D. Epidemiological, clinical and radiological aspects of osteopoikilosis. J Bone Joint Surg [Br] 1992;74:504-6.

2. Pimentel R, Ignácio H, Barcellos L, Lopes LTA. Osteopoiquilose: relato de um caso. Rev Bras Ortop 1990;25:406-8.

3. Ayling RM, Evans PEL. Giant cell tumor in a patient with osteopoikilosis. Acta Orthop Scand 1988;59:74-6.

4. Resnick D, Niwayama G. Enostoses, hyperostosis and periostitis. In: Diagnosis of bone and joint disorders. 3rd ed. Philadelphia: WB Saunders, 1981.

5. Mindell ER, Northup CS, Douglas HO Jr. Osteosarcoma associated with osteopoikilosis: case report. J Bone Joint Surg [Am] 1978;60:406-8.

6. Grimer RJ, Davies AM, Starkie CM, Sneath RS. Chondrosarcoma in a patient with osteopoikilosis. Apropos of a case. Rev Chir Orthop Reparatrice Appar Mot 1989;75:188-90.

7. Caffey J. Pediatric X-ray diagnosis. 7th ed. Chicago: Year Book Med Publ, 1978.

8. Dahan S, Bonafé JL, Laroche M, Rousseau H, Railhac JJ. Iconographie du syndrome du Buschke-Ollendorff: étude tomodensitométrique et en résonance magnétique de l'ostéopoecilie. Ann Dermatol Venereol 1989;116:229-30. 